\title{
Article \\ Hot Oscillatory Pressing of Carbon Nanotube-Reinforced Copper Matrix Nanocomposite
}

\author{
Min Han ${ }^{1}$, Yunpeng Ding ${ }^{1, *}\left(\mathbb{0}\right.$, Jinbiao Hu ${ }^{1}$, Zhiai Shi ${ }^{1}$, Sijia Jiao ${ }^{1}$, Xiaoqin Guo ${ }^{1, *}$, Hanying Wang ${ }^{1}$ \\ and Linan An ${ }^{2}$ \\ 1 School of Materials, Zhengzhou University of Aeronautics, Zhengzhou 450046, China; \\ hanmin188@126.com (M.H.); jinbiao2021@126.com (J.H.); szhiai@126.com (Z.S.); jiaosijia@126.com (S.J.); \\ hanyingwang@126.com (H.W.) \\ 2 Department of Materials Science and Engineering, University of Central Florida, Orlando, FL 32816, USA; \\ linan74@gmail.com \\ * Correspondence: yunpengding@zua.edu.cn (Y.D.); guoxq@zua.edu.cn (X.G.)
}

check for updates

Citation: Han, M.; Ding, Y.; Hu, J.; Shi, Z.; Jiao, S.; Guo, X.; Wang, H.; An, L. Hot Oscillatory Pressing of Carbon Nanotube-Reinforced Copper Matrix Nanocomposite. Nanomaterials 2021, 11, 2411. https://doi.org/10.3390/ nano11092411

Academic Editor: Werner Blau

Received: 12 August 2021

Accepted: 13 September 2021

Published: 16 September 2021

Publisher's Note: MDPI stays neutral with regard to jurisdictional claims in published maps and institutional affiliations.

Copyright: (C) 2021 by the authors. Licensee MDPI, Basel, Switzerland. This article is an open access article distributed under the terms and conditions of the Creative Commons Attribution (CC BY) license (https:/ / creativecommons.org/licenses/by/ $4.0 /)$.

\begin{abstract}
Carbon nanotube reinforced copper matrix nanocomposites have great potential in machinery, microelectronics, and other applications. The materials are usually prepared by powder metallurgy processes, in which consolidation is a key step for high performance. To improve the density and mechanical properties, the authors explored the use of hot oscillatory pressing (HOP) to prepare this material. A carbon nanotube reinforced copper matrix nanocomposite was synthesized by both HOP and hot pressing (HP) at various temperatures, respectively. The samples prepared by HOP exhibited significantly higher density and hardness than those prepared by HP at the same temperature, and this was because the oscillatory pressure of HOP produced remarkable plastic deformation in copper matrix during sintering. With the decrease of sintering temperature in HOP, the amount of deformation defect increased gradually, playing a key role in the increasing hardness. This work proves experimentally for the first time that HOP can produce much more plastic deformation than HP to promote densification, and that HOP could be a very promising technique for preparing high-performance carbon nanotube reinforced copper matrix nanocomposites.
\end{abstract}

Keywords: carbon nanotube; copper matrix nanocomposite; hot oscillatory pressing; densification; hardness

\section{Introduction}

Carbon nanotube reinforced copper matrix nanocomposites (CNT/Cu nanocomposites) have great potential in machinery, microelectronics, new energy, and other applications due to the high strength and conductivity as well as good chemical stability [1,2]. The materials are usually prepared by powder metallurgy processes, in which consolidation is a key step that has a great effect on the microstructures and properties of resultant materials [3,4]. Due to the poor wettability between $\mathrm{CNT}$ and $\mathrm{Cu}$ [5], consolidation of $\mathrm{CNT} / \mathrm{Cu}$ nanocomposites is not as easy as it seems, especially when the CNT content is high. When conventional sintering techniques are used, long sintering time and high sintering temperature are required for densifying the materials [6]. The resultant materials usually exhibited low relative density and coarse-grained structures; thus, they required subsequent deformation (e.g., forging, extrusion, and rolling [7]) to further increase density $[8,9]$. However, the subsequent deformation can damage the structure of CNTs and the properties of the material [10].

In recent years, to improve the density and mechanical property, CNT/Cu nanocomposites were also prepared using some new sintering technologies, such as spark plasma sintering (SPS) [11], microwave sintering (MS) [12], and laser sintering (LS) [13,14]. Zhang et al. [11] showed that SPS can significantly shorten the sintering time, likely by improving the surface activity of copper powder and enhancing atomic diffusion. They prepared the 
nanocomposite containing 3 vol.\% of CNTs with density up to $98.9 \%$ and inhibited grain growth, which exhibited a strength nearly double that of the matrix. Duan et al. [12] prepared CNT/Cu composites with density of $95 \%$ and Vickers hardness of 80 by microwave sintering at $1000{ }^{\circ} \mathrm{C}$. Stasic et al. [13] and Gu et al. [14] used high energy laser sintering to prepare high-strength particle-reinforced copper matrix composites with density up to $98 \%$ and $90.7 \%$, respectively. Except for SPS, other new techniques did not lead to significant improvement in preparation of CNT/Cu nanocomposites.

Recently, a unique sintering technology-hot oscillatory pressing (HOP, or oscillatory pressure sintering) - was developed [15], which uses oscillatory pressure to replace constant pressure in traditional hot pressing (HP). HOP was applied to many ceramic materials such as WC [16], zirconia [17], alumina [18], silicon nitride [19], aluminum nitride [20], and high entropy ceramic [21], as well as refractory alloy [22] and cemented carbide [23,24]. HOP can enhance densification, inhibit grain growth, and improve mechanical properties of these materials. Several possible mechanisms were speculated to explain such improvements, including that the oscillatory pressure of $\mathrm{HOP}$ can promote particle rearrangement, enhance the sliding of grain boundary, and generate plastic deformation [25-27], though there is little experimental evidence about these mechanisms.

In this paper, we report for the first time the preparation of $\mathrm{CNT} / \mathrm{Cu}$ nanocomposites by HOP. Compared with that of HP, HOP can significantly improve the density and mechanical property of the resultant materials. We demonstrate that such improvements are credited to the oscillatory pressure of HOP, which can generate remarkable plastic deformation during sintering.

\section{Materials and Methods}

Commercially available copper powder (purity 99.9\%, diameter $0.5 \mu \mathrm{m}$, Nanou Co., Ltd., Shanghai, China) and CNT (outer diameter 30-50 nm, length 10-20 $\mu \mathrm{m}$, Chinese Academy of Sciences, Chengdu Organic Chemistry Co., Ltd., Chengdu, China) were employed as the original materials. The received CNTs were coated by $\mathrm{Cu}$ using electroless plating method [28]. The received $\mathrm{Cu}$ powder and 3 vol.\% of $\mathrm{Cu}$-coated CNTs were placed in a steel vial and then mixed by ball milling under argon atmosphere in the mill at $300 \mathrm{rpm}$ for $2 \mathrm{~h}$. Zirconia balls of $5 \mathrm{~mm}$ were employed as the milling medium and the ball-to-material weight ratio was 10:1. The mixture of powder was then placed into a cylinder-shaped graphite die with an inner radius of $7.5 \mathrm{~mm}$ and sintered in the hot oscillatory pressing system (OPS 2020, Efield Materials Technology Co., Ltd., Chengdu, China). The sintering schedule of HOP was as follow. Firstly, the samples were heated to the sintering temperature $\left(550,600,650\right.$ and $\left.700{ }^{\circ} \mathrm{C}\right)$ at a heat-up rate of $8{ }^{\circ} \mathrm{C} / \mathrm{min}$ with a pressure of $40 \mathrm{MPa}$ in a vacuum $(<10 \mathrm{~Pa})$. Then, the sample was held at the sintering temperature for $60 \mathrm{~min}$ under either an oscillatory pressure of $40 \pm 10 \mathrm{MPa}$ with a frequency of $5 \mathrm{~Hz}(\mathrm{HOP})$ or an invariable pressure of $40 \mathrm{MPa}(\mathrm{HP})$. Finally, the samples were cooled down to RT with a cooling rate of $15 \mathrm{~K} / \mathrm{min}$. The detailed sintering schedule of $\mathrm{HOP}$ and HP is shown in Figure 1.

Relative density was the ratio of measured density to theoretical density, which was used to characterize the degree of densification in materials. The Archimedes method was adopted to measure the density of sintered samples. The theoretical density was the sum of the product of the density and corresponding volume fraction for each component in the composite. The microhardness tests were carried out on the polished samples under a load of $500 \mathrm{~g}$ for $15 \mathrm{~s}$. Then, the samples were characterized by scanning electron microscope (SEM, JSM-7001F, JEOL, Tokyo, Japan), electron back-scattered diffraction (EBSD, HKL Nordlys Nano, Oxford, Oxford, UK) and transmission electron microscope (TEM, JEM-2100, JEOL, Tokyo, Japan). The SEM samples were prepared by etching the polished surface of the sintered samples. Before EBSD test, the surface of samples was mechanically polished and electropolished in perchloric acid solution. During EBSD test, for each specimen, an area of $20 \times 20 \mu \mathrm{m}$ were scanned with a step size of $60 \mathrm{~nm}$. Channel 5 software (5.1, Oxford, Oxford, UK) was employed as the analysis software. During EBSD analysis, the 
average value of MAD (mean angular deviation) of each specimen was as follows: 0.47 $\left(\mathrm{HOP} 550^{\circ} \mathrm{C}\right), 0.43\left(\mathrm{HOP} 600^{\circ} \mathrm{C}\right), 0.45\left(\mathrm{HOP} 650^{\circ} \mathrm{C}\right), 0.43\left(\mathrm{HOP} 700{ }^{\circ} \mathrm{C}\right), 0.4\left(\mathrm{HP} 550{ }^{\circ} \mathrm{C}\right)$, and $0.32\left(\mathrm{HP} 700^{\circ} \mathrm{C}\right)$, respectively. TEM specimens were prepared by grinding and ion polishing.

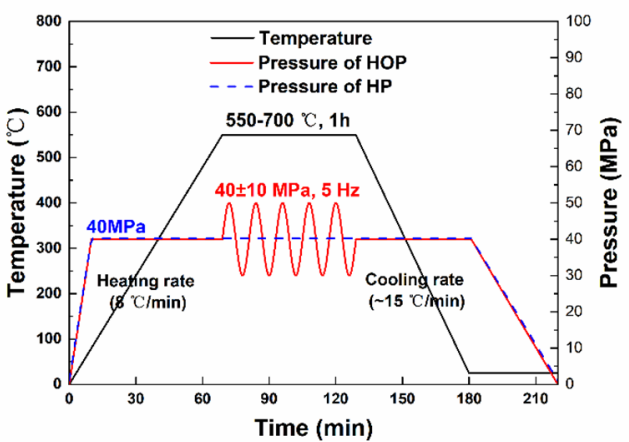

Figure 1. Detailed sintering schedule of HOP and HP.

\section{Results}

\subsection{Microstructure, Density and Hardness}

Figure 2 exhibits the morphology of the CNTs, Cu-coated CNTs, Cu powder, and mixture of $\mathrm{Cu}$ and $\mathrm{CNT}$ powders. As shown in Figure 2a, the outer diameter of asreceived CNTs is about $30-50 \mathrm{~nm}$. After the process of electroless plating, copper particles are attached to the surface of as-received CNTs (Figure 2b), which is beneficial to the future processing. The as-received $\mathrm{Cu}$ powder have a spherical shape, with a diameter of $0.2-1 \mu \mathrm{m}$, and the mean diameter is about $0.5 \mu \mathrm{m}$ (Figure 2c). After ball milling, the CNTs are evenly embedded into the copper particles (Figure 2d) by the impact and friction processes during milling [29], which can help to make the distribution of CNTs and $\mathrm{Cu}$ powder more uniform. The length of CNTs is about $1 \mu \mathrm{m}$ in the mixture, much shorter than their as-received length, illustrating that ball-milling significantly cut the CNTs.

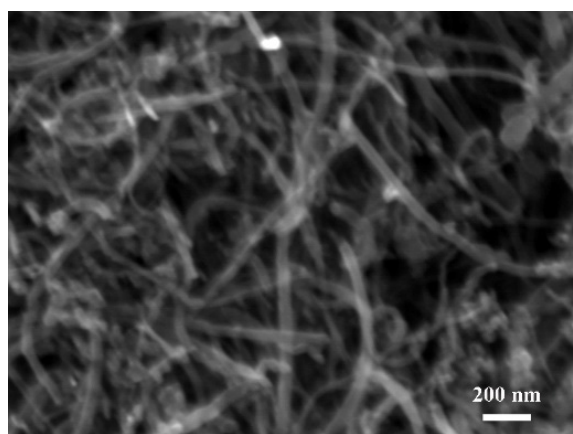

(a)

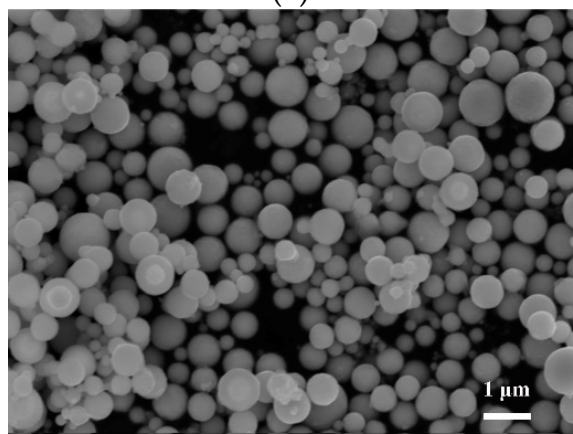

(c)

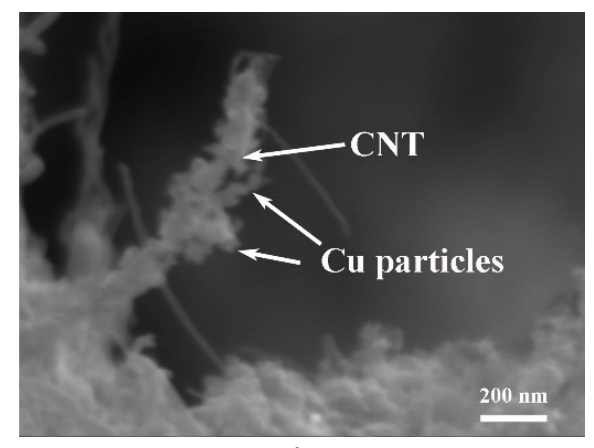

(b)

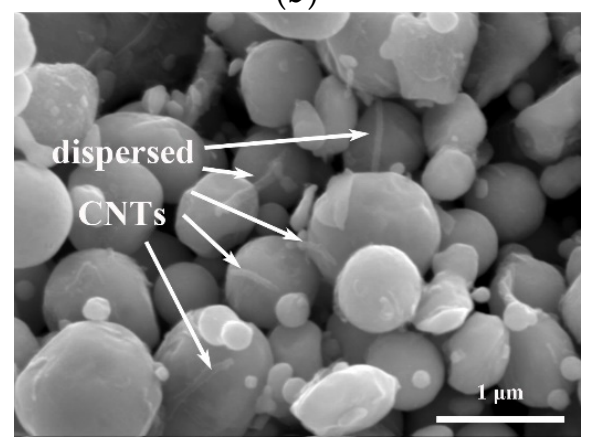

(d)

Figure 2. SEM images of (a) as-received CNTs, (b) Cu-coated CNTs, (c) pure Cu powder, and (d) mixture of CNT and $\mathrm{Cu}$ powders. 
Figure 3 shows the relative density of samples sintered by HOP and HP at different sintering temperatures. Compared with that of HP, HOP can significantly improve the densification of the $\mathrm{CNT} / \mathrm{Cu}$ nanocomposite. While the density of the samples prepared by both techniques increases as the sintering temperature increases, the sample prepared by HOP exhibits much higher density than that of the sample prepared by HP at the same sintering temperature. The sample prepared by $\mathrm{HOP}$ at $550{ }^{\circ} \mathrm{C}$ has the same density as the sample prepared by HP at $650{ }^{\circ} \mathrm{C}$, which indicates that the oscillatory pressure can remarkably reduce the sintering temperature. The density of the sample prepared by HOP at $700{ }^{\circ} \mathrm{C}$ reaches $99.5 \%$, which is higher than most similar materials prepared by other techniques reported in the literature [12,30-32].

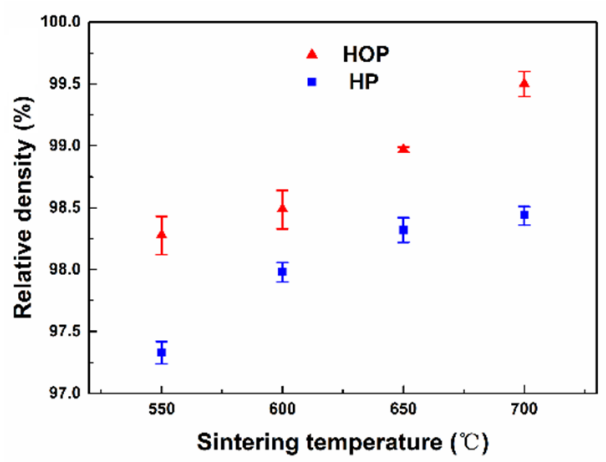

Figure 3. A plot of relative density as a function of sintering temperature for samples sintered by $\mathrm{HOP}$ and HP, respectively.

The microstructure of the obtained samples was characterized by SEM, EBSD, and TEM. Figure 4 shows the typical results obtained from the sample prepared by HOP at $550{ }^{\circ} \mathrm{C}$.

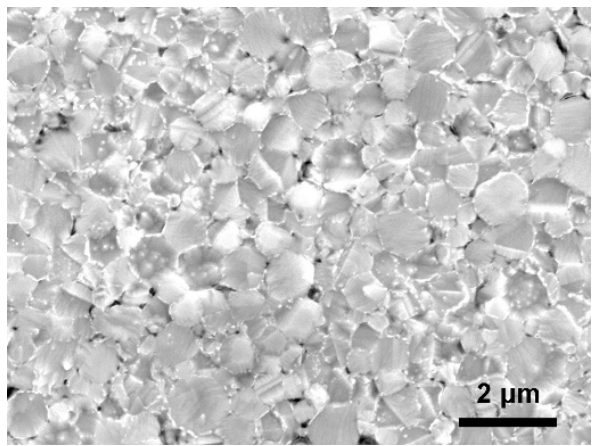

(a)

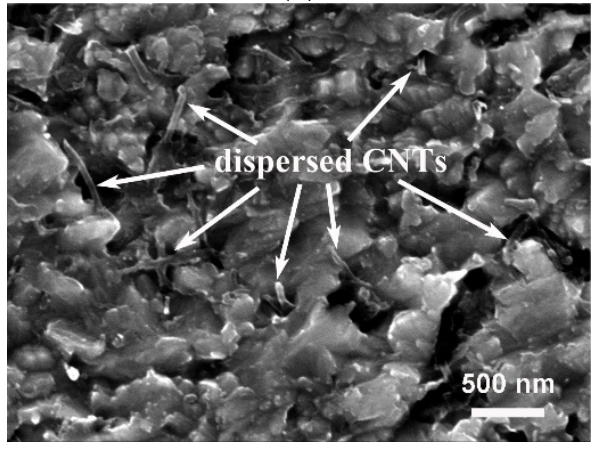

(c)

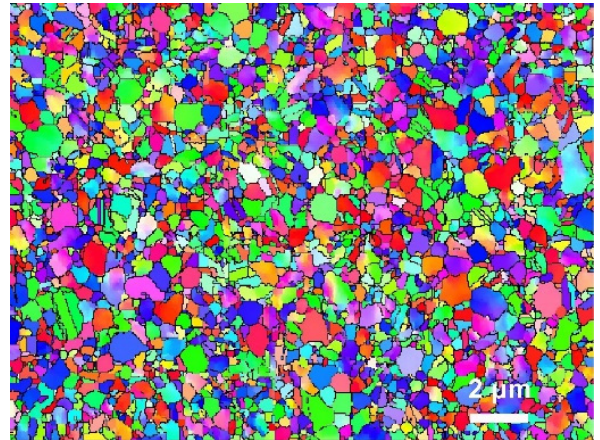

(b)

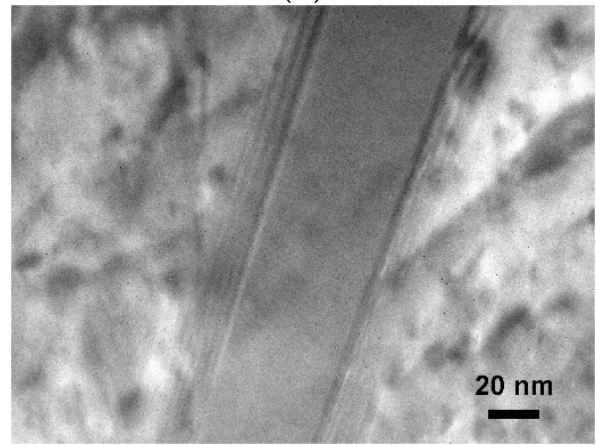

(d)

Figure 4. Microstructure of sample prepared by HOP at $550{ }^{\circ} \mathrm{C}$. (a) SEM and (b) EBSD images showing microstructure. (c) SEM image of over-etched sample showing distribution of CNTs. (d) TEM image of a CNT in the Cu matrix. 
Figure $4 \mathrm{a}, \mathrm{b}$ reveal that the composite exhibits a dense and uniform microstructure without discontinuous grain growth. The average grain size of the matrix measured from SEM images is $\sim 0.60 \mu \mathrm{m}$, which is the same as the particle size of the original copper powder, suggesting that there is almost no grain growth during densification. Figure $4 \mathrm{c}$ is the SEM image obtained from the over-etched polished surface, which reveals that CNTs are uniformly distributed in the matrix.

Figure $4 \mathrm{~d}$ is the TEM of a CNT within the matrix, and the CNT exhibits good integrity. Besides length reduction, CNTs were not further damaged by ball milling and consolidation. The interface between the CNT and the matrix is clean, indicating no reaction between the two. Comparing the results obtained from different samples shows that the microstructure of all samples is almost identical regardless of processing conditions.

The mechanical behavior of the obtained samples was investigated by measuring their hardness. The result (Figure 5) shows that the sample prepared by HOP exhibits much higher hardness than that of the sample prepared by HP at the same temperature, suggesting HOP can improve the mechanical behavior of the nanocomposite. The highest hardness is observed for the sample prepared by $\mathrm{HOP}$ at $550{ }^{\circ} \mathrm{C}$, reaching $159 \mathrm{HV}$. This value is much higher than that observed for the samples prepared by HP at 650 and $700{ }^{\circ} \mathrm{C}$ even though they have the same density and microstructure. The value is also higher than that of the previously reported CNT/Cu nanocomposites with the similar CNT concentration [12,30-32].

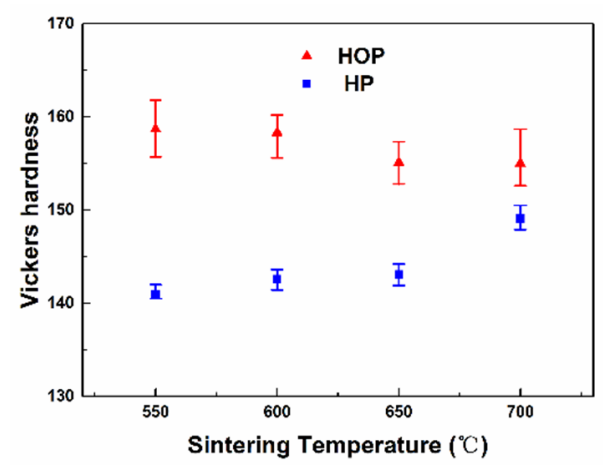

Figure 5. A plot of hardness as a function of sintering temperature for samples sintered by HOP and HP.

Moreover, the authors compare the relative density and hardness of $\mathrm{Cu}$-based materials fabricated by different sintering methods in literatures $[12,30,31,33,34]$ and the current nanocomposite sintered by HOP exhibits higher relative density and hardness than any others. In particular, the HOP sample shows higher hardness than that of the SPS sample [33,34], though with similar relative density. Furthermore, in Figure 5, the hardness of the sample prepared by HP increases with increasing sintering temperature, which is easy to understand since the samples exhibit the same microstructure but higher density as sintering temperature increases. However, there is no significant difference in the hardness of the samples sintered by HOP at different temperatures, even though the density of sample increases with temperature.

\subsection{Distribution of Grain Boundaries and Deformation Defect}

To uncover the mechanisms responsible for the observed densification and mechanical behavior, the samples were further analyzed using EBSD in detail (Figure 6a-f). The blue, orange, black, and red lines represent the grain boundaries with the misorientation angles less than $2^{\circ}$ (subgrain boundaries, SGBs), the misorientation angles between 2 to $10^{\circ}$ (low-angle grain boundaries, LAGBs), the misorientation angles $>10^{\circ}$ (high-angle grain boundaries, HAGBs), and the misorientation angle of $60^{\circ}$ (twin boundaries, TBs), respectively. The sample prepared by HOP contains much more small-angle grain boundaries (SAGBs, including SGBs and LAGBs) than that of the sample prepared by HP. 

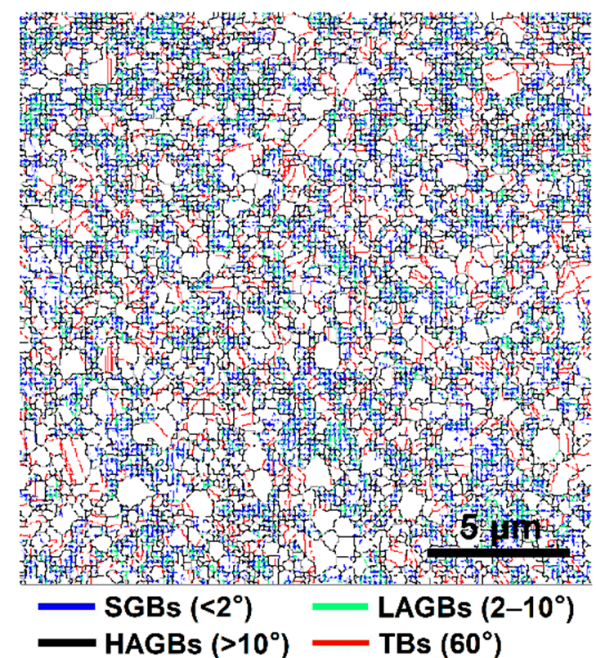

(a)
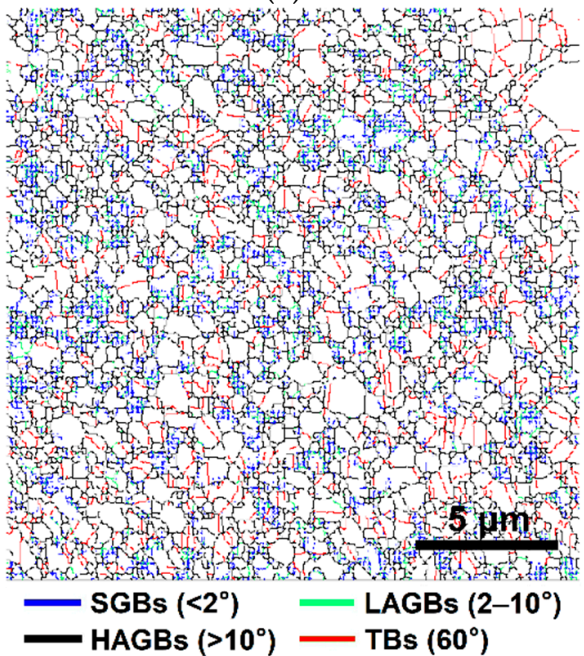

(d)

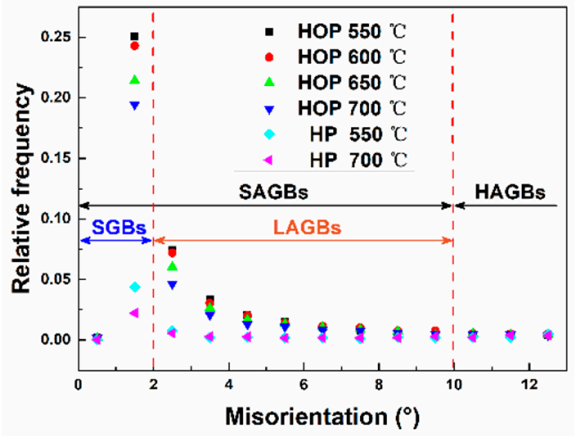

(g)

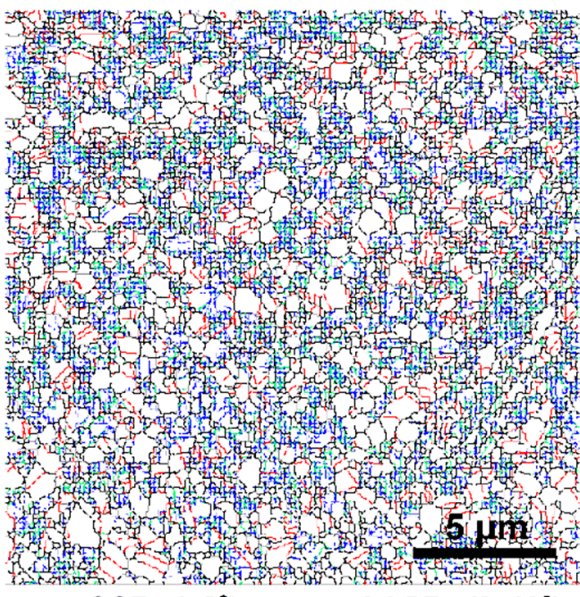

SGBs $\left(<2^{\circ}\right)=$ LAGBs $\left(2-10^{\circ}\right)$ HAGBs $\left(>10^{\circ}\right)-\operatorname{TBs}\left(60^{\circ}\right)$

(b)

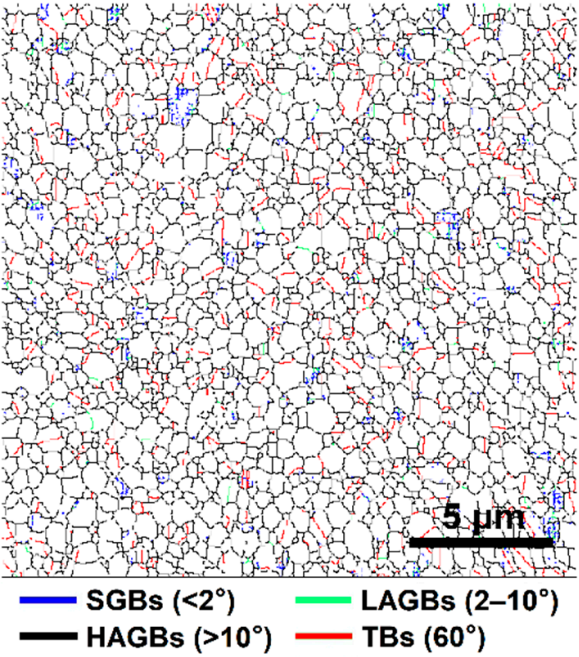

(e)

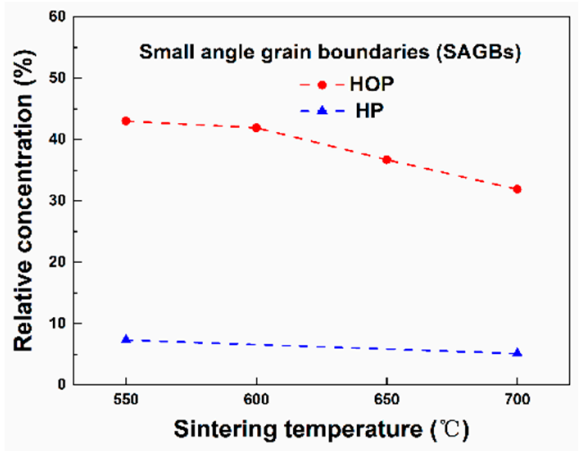

(h)

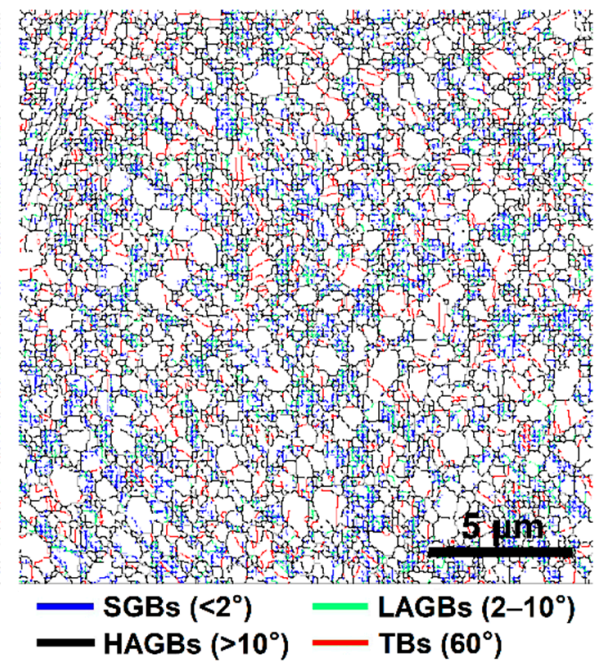

(c)
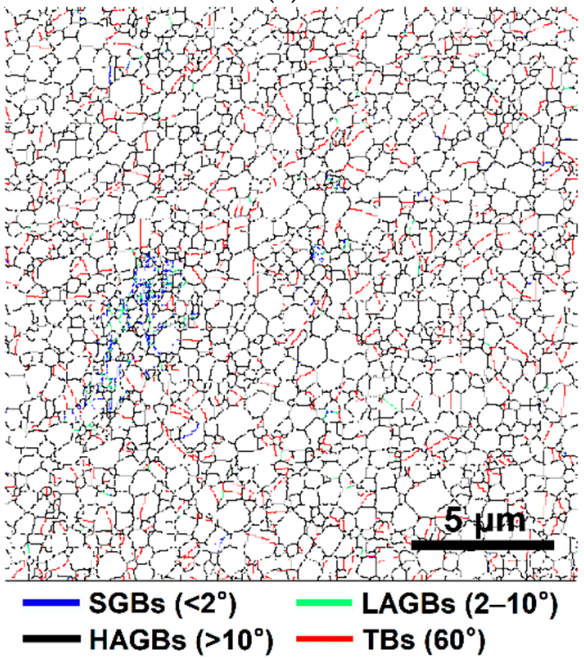

(f)

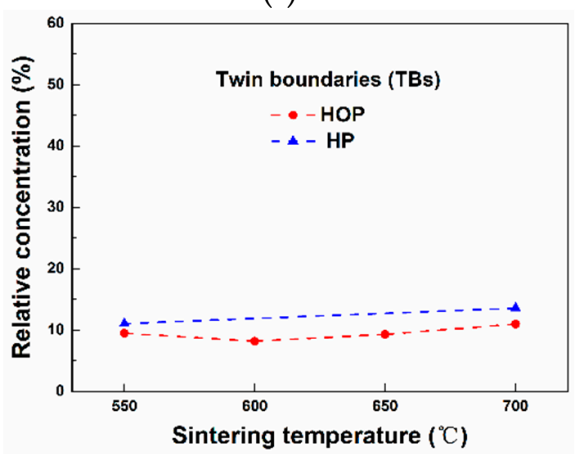

(i)

Figure 6. (a-f) EBSD maps of grain boundary for samples prepared by (a) HOP at $550{ }^{\circ} \mathrm{C},(\mathbf{b}) \mathrm{HOP}$ at $600{ }^{\circ} \mathrm{C}$, (c) $\mathrm{HOP}$ at $650{ }^{\circ} \mathrm{C}$, (d) $\mathrm{HOP}$ at $700{ }^{\circ} \mathrm{C}$, (e) $\mathrm{HP}$ at $550{ }^{\circ} \mathrm{C}$, and (f) $\mathrm{HP}$ at $700{ }^{\circ} \mathrm{C}$, respectively. (g) Probability distribution of grain boundaries as a function of misorientation angles for sintered samples. (h,i) Relative concentration of small-angle grain boundaries and twin boundaries as a function of sintering temperature, respectively, for samples sintered by HOP and HP, respectively.

Figure $6 \mathrm{~g}$ plots the distribution of grain boundaries as a function of misorientation angles for the sintered samples. The plots confirm that the samples prepared by HOP contain much more SAGBs than that of the sample prepared by HP. Figure 6h illustrates the effect of sintering temperature on the concentration of SAGBs. The sample prepared 
by HOP contains more than 5 times the amount of SAGBs than the samples prepared by HP. The SAGBs content of the samples prepared by HOP and HP decreases as sintering temperature increases. Figure $6 \mathrm{i}$ is a plot of TBs content as a function of sintering temperature, which reveals that the concentration of TBs in the sample prepared by HOP and HP is almost the same and remains unchanged with the increase of sintering temperature.

Figure 7 are deformation fraction maps of the samples prepared by HOP and HP at different temperatures, respectively. The area of plastic deformation in the sample prepared by HOP is much larger than that of the sample prepared by HP. The fraction of deformation area was measured from EBSD maps and plotted as a function of sintering temperature in Figure 8 . The deformation area of the samples prepared by HOP is 4 to 8 times that of the samples prepared by HP. The deformation area in the samples prepared by HOP and HP decreases as sintering temperature increases.

The plastic deformation in the nanocomposite was further studied by TEM, as shown in Figure 9. The results reveal that the samples prepared by HOP contain a larger number of lattice defects, such as dislocations (Figure 9a) and dislocation walls (Figure 9b), while such dislocation activity was not observed from the samples prepared by HP (Figure 9c). This indicates that the oscillatory pressure of HOP produces much more dislocations than the static pressure of HP.

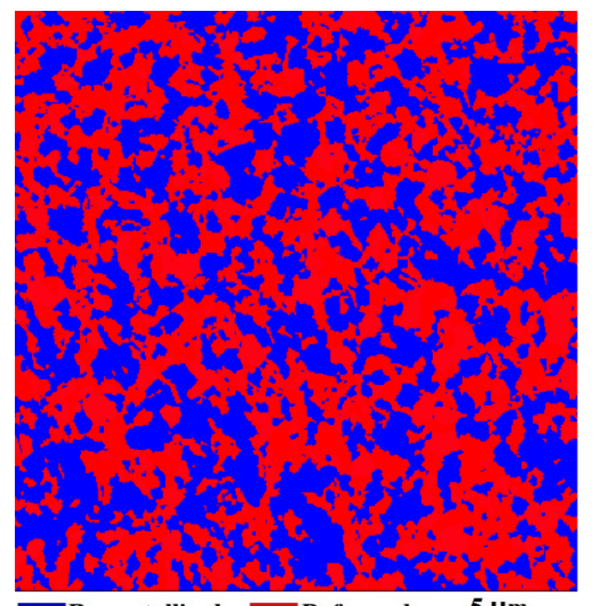

Recrystallized

(a)

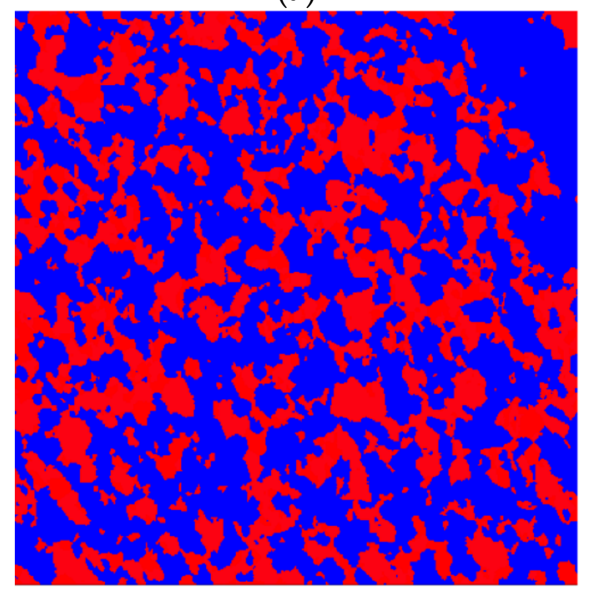

Recrystallized

(d)
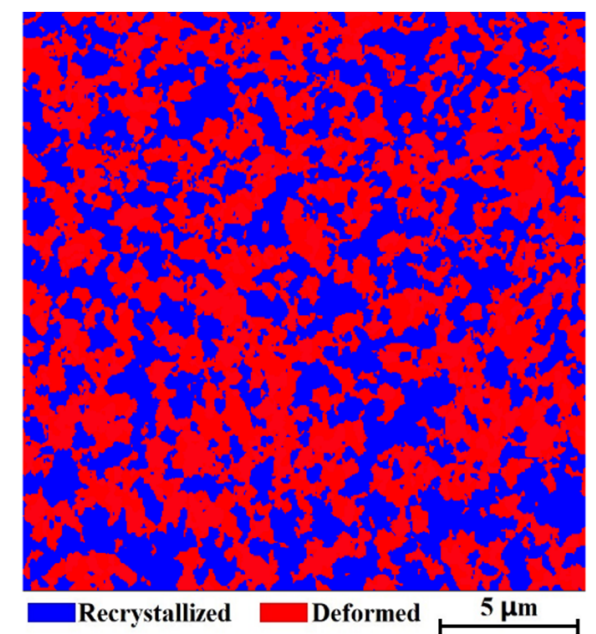

(b)

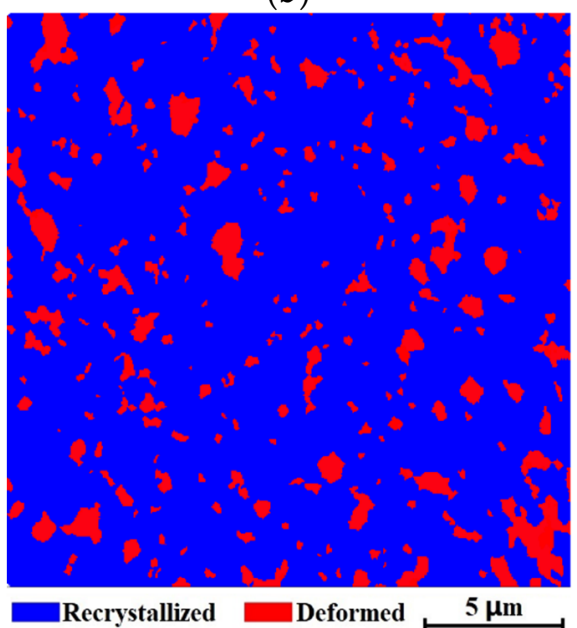

(e)
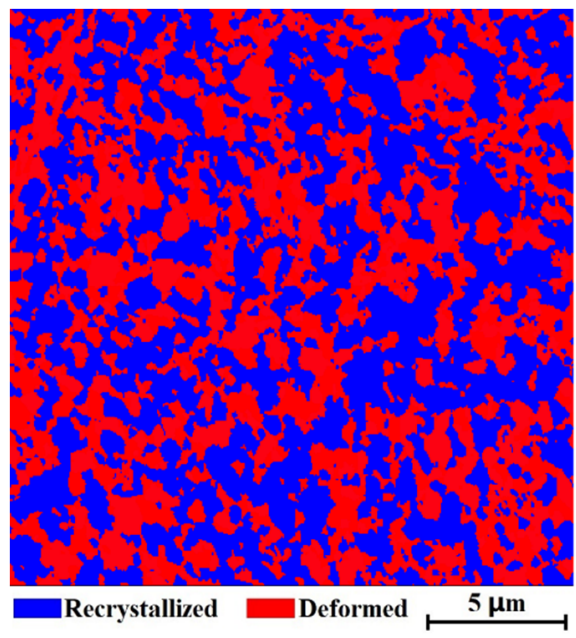

(c)

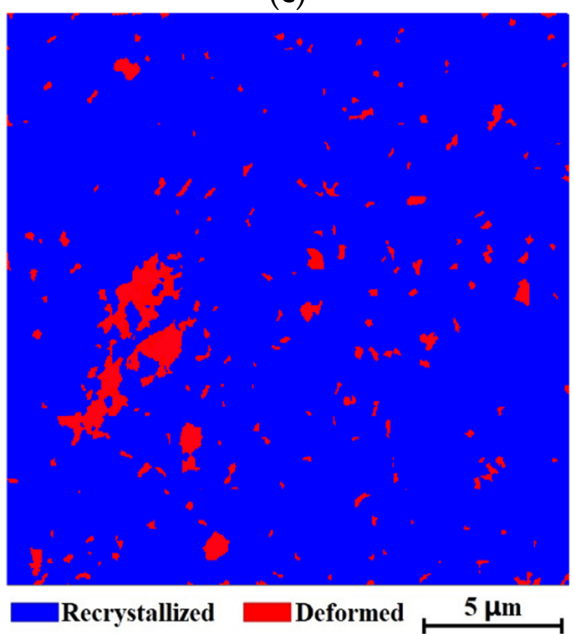

(f)

Figure 7. Deformation fraction maps of samples prepared by (a) HOP at $550{ }^{\circ} \mathrm{C}$, (b) $\mathrm{HOP}$ at $600{ }^{\circ} \mathrm{C}$, (c) $\mathrm{HOP}$ at $650{ }^{\circ} \mathrm{C}$, (d) $\mathrm{HOP}$ at $700{ }^{\circ} \mathrm{C}$, (e) $\mathrm{HP}$ at $550{ }^{\circ} \mathrm{C}$, and (f) $\mathrm{HP}$ at $700^{\circ} \mathrm{C}$, respectively. 


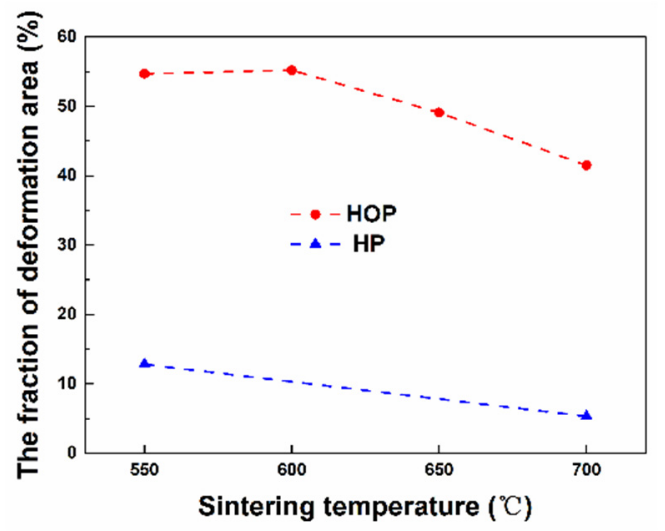

Figure 8. Fraction of deformation area as a function of sintering temperature for samples sintered by HOP and HP.

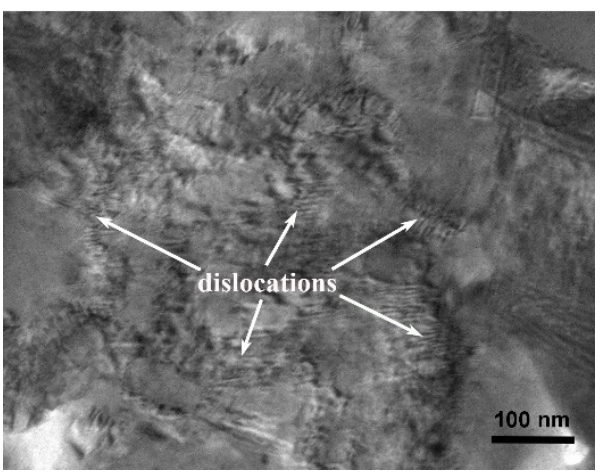

(a)

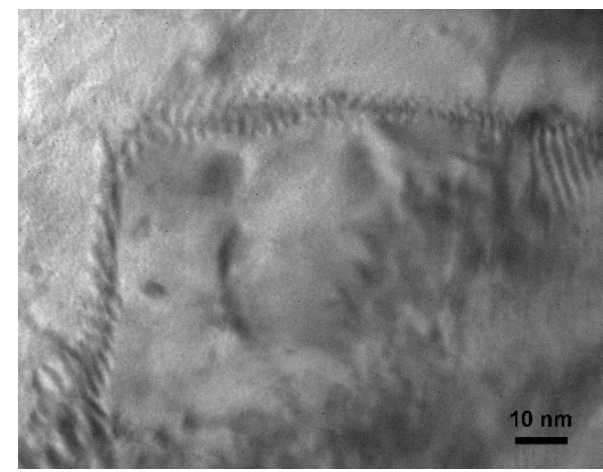

(b)

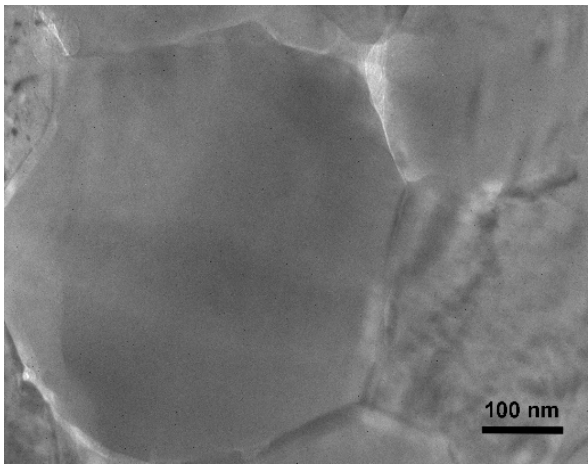

(c)

Figure 9. TEM images of samples prepared by (a,b) HOP and (c) $\mathrm{HP}$ at $550{ }^{\circ} \mathrm{C}$.

\section{Discussion}

The above results (Figures 6-9) clearly reveal that compared with that of HP, HOP produced much more plastic deformation via the generation and motion of dislocations, instead of twinning. This can be rationalized as follows. The dislocation density should be proportional to the plastic deformation strain that happened during densification. Although the apparent plastic strain, which is proportional to the increases in density during sintering (assume the fraction of deformation strain is the same for all samples), is similar for the samples prepared by HOP as for the samples prepared by HP, the "real" total plastic strain in the samples prepared by HOP should be much greater than in those prepared by HP due to the repeated deformations caused by the oscillatory pressure of HOP. The decrease in plastic deformation with increasing sintering temperature (Figure 7) is likely due to the balance between dislocation formation and recrystallization. The high dislocation density produced by deformation can provide driving force and nucleation 
sites for recrystallization at high temperature, which leads to the removal of lattice defects. In the temperature rang tested here, the balance shifts to the recrystallization as the sintering temperature increases, resulting in the decrease in the density of lattice defects (Figures 6 and 7).

The above results can also be used to rationalize the trend of hardness changes observed from different samples. Since the samples prepared by HOP exhibit significant plastic deformation, it is reasonable to expect that the hardness of the samples is determined by the degree of plastic deformation and their relative density. On the other hand, the hardness of the samples prepared by HP is determined by their relative density. Thus, the increase in hardness exhibited by the samples prepared by HOP (Figure 5) is due to the strain hardening effect. For example, although they have the same density and grain size, the samples prepared by HOP at $550{ }^{\circ} \mathrm{C}$ have higher hardness than those prepared by HP at $650^{\circ} \mathrm{C}$ since the former has greater plastic deformation. The hardness of the samples prepared by HP increases with higher temperature (Figure 5). This is due to the increase of relative density with higher temperature (Figure 3). On the other hand, the weak effect of sintering temperature on the hardness of the samples prepared by HOP (Figure 5) is the trade-off between the degree of plastic deformation, which decreases with temperature and relative density, which increases with temperature (Figure 3).

From the above, this paper proves for the first time that the improvements in densification and mechanical properties exhibited by HOP-prepared materials are due to the plastic deformation produced by the oscillatory pressure, as speculated by the literatures $[25,26,35]$.

\section{Conclusions}

In this paper, CNTs/Cu nanocomposite with 3 vol.\% of multiwall carbon nanotubes was prepared by both hot oscillatory pressing (HOP) and hot pressing (HP) at different temperatures ranging from 550 to $700{ }^{\circ} \mathrm{C}$. The results led to the following conclusions:

(1) Compared to that of HP, the samples prepared by HOP exhibited significantly higher density and hardness.

(2) The improved densification of HOP is because the oscillatory pressure caused plastic deformation, and the improved hardness is due to the strain-hardening effect.

(3) With the decrease of sintering temperature in HOP, the amount of deformation defects increased gradually, playing a key role in the increasing hardness.

This work proves experimentally for the first time that HOP can produce much more plastic deformation than HP to promote densification and improve hardness. Therefore, the current study suggests that HOP is a promising technique for the preparation of high-performance CNT/Cu nanocomposites.

Supplementary Materials: The Supplementary Materials are available online at https:/ /www.mdpi. com/article/10.3390/nano11092411/s1.

Author Contributions: Conceptualization, Y.D.; investigation, Y.D., L.A. and M.H.; data curation, M.H.; writing—original draft preparation, Y.D., L.A. and M.H.; writing—review and editing, Y.D.; visualization, J.H., Z.S., S.J., X.G. and H.W.; supervision, Y.D. and X.G.; project administration, L.A. and X.G. All authors have read and agreed to the published version of the manuscript.

Funding: This research was funded by Natural Science Foundation of Henan Province, China, grant number 202300410487.

Data Availability Statement: The data presented in this study are available in Supplementary Materials.

Conflicts of Interest: The authors declare no conflict of interest. 


\section{References}

1. Park, S.; Gupta, A.P.; Yeo, S.J.; Jung, J.; Paik, S.H.; Mativenga, M.; Kim, S.H.; Shin, J.H.; Ahn, J.S.; Ryu, J. Carbon Nanotube Field Emitters Synthesized on Metal Alloy Substrate by PECVD for Customized Compact Field Emission Devices to Be Used in X-Ray Source Applications. Nanomaterials 2018, 8, 378. [CrossRef]

2. Carneiro, I.; Viana, F.; Vieira, M.F.; Fernandes, J.V.; Simões, S. EBSD Analysis of Metal Matrix Nanocomposite Microstructure Produced by Powder Metallurgy. Nanomaterials 2019, 9, 878. [CrossRef] [PubMed]

3. Radhamani, A.V.; Lau, H.C.; Ramakrishna, S. CNT-reinforced metal and steel nanocomposites: A comprehensive assessment of progress and future directions. Compos. Part A Appl. Sci. Manuf. 2018, 114, 170-187. [CrossRef]

4. Cho, S.; Kikuchi, K.; Miyazaki, T.; Takagi, K.; Kawasaki, A.; Tsukada, T. Multiwalled carbon nanotubes as a contributing reinforcement phase for the improvement of thermal conductivity in copper matrix composites. Scr. Mater. 2010, 63, 375-378. [CrossRef]

5. Yan, F.; Liu, L.; Li, M.; Zhang, M.; Shang, L.; Xiao, L.; Ao, Y. One-step electrodeposition of Cu/CNT/CF multiscale reinforcement with substantially improved thermal/electrical conductivity and interfacial properties of epoxy composites. Compos. Part A—Appl. Sci. Manuf. 2019, 125, 105530. [CrossRef]

6. Jiang, Y.; Wang, C.; Liang, S.; Ren, J.; Du, X.; Liu, F. TiB2 (-TiB)/Cu in-situ composites prepared by hot-press with the sintering temperature just beneath the melting point of copper. Mater. Charact. 2016, 121, 76-81. [CrossRef]

7. Meng, L.; Wang, X.; Hu, X.; Shi, H.; Wu, K. Role of structural parameters on strength-ductility combination of laminated carbon nanotubes/copper composites. Compos. Part A-Appl. Sci. Manuf. 2019, 116, 138-146. [CrossRef]

8. Arnaud, C.; Lecouturier, F.; Mesguich, D.; Ferreira, N.; Chevallier, G.; Estournès, C.; Weibel, A.; Laurent, C. High strength—High conductivity double-walled carbon nanotube-Copper composite wires. Carbon 2016, 96, 212-215. [CrossRef]

9. Akbarpour, M.R.; Mousa Mirabad, H.; Alipour, S.; Kim, H.S. Enhanced tensile properties and electrical conductivity of Cu-CNT nanocomposites processed via the combination of flake powder metallurgy and high pressure torsion methods. Mat. Sci. Eng. A 2020, 773, 1-10. [CrossRef]

10. Dong, S.R.; Tu, J.P.; Zhang, X.B. An investigation of the sliding wear behavior of Cu-matrix composite reinforced by carbon nanotubes. Mat. Sci. Eng. A 2001, 313, 83-87. [CrossRef]

11. Wang, H.; Zhang, Z.; Hu, Z.; Wang, F.; Li, S.; Korznikov, E.; Zhao, X.; Liu, Y.; Liu, Z.; Kang, Z. Synergistic strengthening effect of nanocrystalline copper reinforced with carbon nanotubes. Sci. Rep. 2016, 6, 1-8. [CrossRef] [PubMed]

12. Duan, B.; Zhou, Y.; Wang, D.; Zhao, Y. Effect of CNTs content on the microstructures and properties of CNTs/Cu composite by microwave sintering. J. Alloys Compd. 2019, 771, 498-504. [CrossRef]

13. Stašić, J.; Trtica, M.; Rajković, V.; Ružić, J.; Božić, D. Laser sintering of Cu-Zr-ZrB2 composite. Appl. Surf. Sci. 2014, 321, 353-357. [CrossRef]

14. Gu, D.; Shen, Y. WC-Co particulate reinforcing Cu matrix composites produced by direct laser sintering. Mater. Lett. 2006, 60, 3664-3668. [CrossRef]

15. Xie, Z.; Li, S.; An, L.; Franks, G. A Novel Oscillatory Pressure-Assisted Hot Pressing for Preparation of High-Performance Ceramics. J. Am. Ceram. Soc. 2014, 97, 1012-1015. [CrossRef]

16. Cheng, Y.; Zhu, T.; Li, Y.; Sang, S.; Liao, N.; Xie, Z.; Dai, J. Microstructure and mechanical properties of oscillatory pressure sintered WC ceramics with different carbon sources. Ceram. Int. 2021, 47, 11793-11798. [CrossRef]

17. Li, J.; Fan, J.; Yuan, Y.; Liu, J.; Zhao, K.; Liu, D.; Xie, Z.; An, L. Effect of oscillatory pressure on the sintering behavior of ZrO2 ceramic. Ceram. Int. 2020, 46, 13240-13243. [CrossRef]

18. Liu, D.; Zhang, X.; Fan, J.; Yuan, Y.; Zhao, K.; Liu, J.; An, L. Sintering behavior and mechanical properties of alumina ceramics exposed to oscillatory pressure at different sintering stages. Ceram. Int. 2021, 47, 23682-23685. [CrossRef]

19. Li, S.; Wei, C.; Zhou, L.; Wang, P.; Wang, W. Microstructure and fracture strength of silicon nitride ceramics consolidated by oscillatory pressure sintering. Ceram. Int. 2019, 45, 15671-15675. [CrossRef]

20. Feng, B.; Zhou, Y.; Peng, C.; Li, X.; Liu, J.; Wang, Y.; Rao, P.; Wu, J. Vibration Assisted Hot-Press Sintering of AlN Ceramics. J. Am. Ceram. Soc. 2015, 98, 1711-1713. [CrossRef]

21. Li, M.; Zhao, X.; Shao, G.; Wang, H.; Zhu, J.; Liu, W.; Fan, B.; Xu, H.; Lu, H.; Zhou, Y.; et al. Oscillatory pressure sintering of high entropy (Zr0.2Ta0.2Nb0.2Hf0.2Mo0.2)B2 ceramic. Ceram. Int. 2021, 47, 8707-8710. [CrossRef]

22. Gao, K.; Xu, Y.; Tang, G.; Fan, L.; Zhang, R.; An, L. Oscillating pressure sintering of W-Ni-Fe refractory alloy. J. Alloys Compd. 2019, 805, 789-793. [CrossRef]

23. Gao, Y.; Gao, K.; Fan, L.; Yang, F.; Guo, X.; Zhang, R.; An, L. Oscillatory pressure sintering of WC-Fe-Ni cemented carbides. Ceram. Int. 2020, 46, 12727-12731. [CrossRef]

24. Zhu, T.; Zhang, J.; An, D.; Xie, Z.; Li, Y.; Sang, S.; Dai, J. Oscillatory pressure sintering: A new method for preparing WC-Co cemented carbides. J. Alloys Compd. 2020, 816, 152521. [CrossRef]

25. Li, S.; Xie, Z.; Xue, W. Microstructure and mechanical properties of zirconia ceramics consolidated by a novel oscillatory pressure sintering. Ceram. Int. 2015, 41, 10281-10286. [CrossRef]

26. Fan, J.; Yuan, Y.; Li, J.; Liu, J.; An, L. Densification and grain growth in oscillatory pressure sintering of alumina toughened zirconia ceramic composites. J. Alloys Compd. 2020, 845, 155644. [CrossRef]

27. Han, Y.; Xie, Z.; Li, S.; Zhu, T.; Wu, W.; An, D.; Hu, F.; Zhai, F. Optimum sintering temperature of high quality silicon nitride ceramics under oscillatory pressure. Ceram. Int. 2018, 44, 6949-6952. [CrossRef] 
28. Song, J.L.; Chen, W.G.; Dong, L.L.; Wang, J.J.; Deng, N. An electroless plating and planetary ball milling process for mechanical properties enhancement of bulk CNTs/Cu composites. J. Alloys Compd. 2017, 720, 54-62. [CrossRef]

29. Suryanarayana, C. Mechanical alloying and milling. Prog. Mater. Sci. 2006, 46, 1-184. [CrossRef]

30. Huang, Z.; Zheng, Z.; Zhao, S.; Dong, S.; Luo, P.; Chen, L. Copper matrix composites reinforced by aligned carbon nanotubes: Mechanical and tribological properties. Mater. Des. 2017, 133, 570-578. [CrossRef]

31. Wang, H.; Zhang, Z.; Zhang, H.; Hu, Z.; Li, S.; Cheng, X. Novel synthesizing and characterization of copper matrix composites reinforced with carbon nanotubes. Mat. Sci. Eng. A 2017, 696, 80-89. [CrossRef]

32. Nayan, N.; Shukla, A.K.; Chandran, P.; Bakshi, S.R.; Murty, S.V.S.N.; Pant, B.; Venkitakrishnan, P.V. Processing and characterization of spark plasma sintered copper/carbon nanotube composites. Mat. Sci. Eng. A 2017, 682, 229-237. [CrossRef]

33. Hamedan, S.S.; Abdi, M.; Sheibani, S. Comparative study on hot rolling of Cu-Cr and Cu-Cr-CNT nanocomposites. Trans. Nonferr. Met. Soc. 2018, 28, 2044-2052. [CrossRef]

34. Pan, Y.; Xiao, S.; Lu, X.; Zhou, C.; Li, Y.; Liu, Z.; Liu, B.; Xu, W.; Jia, C.; Qu, X. Fabrication, mechanical properties and electrical conductivity of Al2O3 reinforced Cu/CNTs composites. J. Alloys Compd. 2019, 782, 1015-1023. [CrossRef]

35. Yao, H.; Shuang, L.; Zhu, T.; Xie, Z. An oscillatory pressure sintering of zirconia powder: Rapid densification with limited grain growth. J. Am. Ceram. Soc. 2017, 100, 2774-2780. 